IRA-International Journal of Education \& Multidisciplinary Studies

ISSN 2455-2526; Vol.05, Issue 01 (2016)

Pg. no. 1-7

Institute of Research Advances

http://research-advances.org/index.php/IJEMS

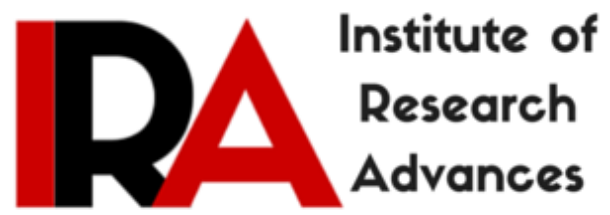

\title{
Some Possible Methods to Introduce Content- Based Instruction (CBI) for the Development of Communication Skills of Technical Students
}

\author{
Dr. Pratibha Mallu \\ Professor-English \\ Vidya Jyothi Institute of Technology, \\ Moinabad, Hyderabad, India.
}

Type of Review: Peer Reviewed.

DOI: http://dx.doi.org/10.21013/jems.v5.n1.p1

\section{How to cite this paper:}

Mallu, P. (2016). Some Possible Methods to Introduce Content-Based Instruction (CBI) for the Development of Communication Skills of Technical Students. IRA International Journal of Education and Multidisciplinary Studies (ISSN 2455-2526), 5(1), 1-7. doi:http://dx.doi.org/10.21013/jems.v5.n1.p1

(C) Institute of Research Advances

(cc) BY-NC

This work is licensed under a Creative Commons Attribution-Non Commercial 4.0 International License subject to proper citation to the publication source of the work.

Disclaimer: The scholarly papers as reviewed and published by the Institute of Research Advances (IRA) are the views and opinions of their respective authors and are not the views or opinions of the IRA. The IRA disclaims of any harm or loss caused due to the published content to any party. 


\section{ABSTRACT}

It is customary in language classrooms to upgrade the teaching methods to make it more learner-centred. Students' attention could be drawn easily towards language learning through the content. The main objective of the present study is, to suggest possible ways to introduce content-based instruction (CBI) for the development of communication skills of technical students. The content of CBI can be teacher presentations, video sequences, guest lecture talks, relevant newspapers articles, scholarly articles, essays, informative texts, etc. Using this content, teachers can conduct student presentations, discussions, JAM sessions, role plays, note taking, summarizing, etc. An ideal content-based instruction class gives equal importance to both content and language through conversations that encourage student language use and development. Taking information from different sources, re-evaluating and restructuring that information can help students to develop very valuable thinking skills that can then be transferred to other subjects. Thus, CBI can be motivating and rewarding.

\section{Introduction}

Content-based instruction has been used in a variety of language learning contexts for the last twenty-five years, though its popularity and wider applicability have increased dramatically in the past ten years (Grabe and Stoller, 1997). It is customary in language classrooms to upgrade the teaching/learning methods to make it more learner-centred. Introduction of content-based instruction for the improvement of communication skills is gaining prominence throughout the world. In Peachey's (2016) observations, recently content-based instruction has become increasingly popular as a means of developing linguistic ability.

The development of content-based language curricula is gaining prominence in a wide range of contexts. A number of factors account for the rise in popularity of CBI (Grabe and Stoller, 1997). Several new and variety of approaches are continuously added to enhance the quality of language classrooms. Introducing multi-disciplinary content in the language classrooms is one among them.

The number of engineering colleges is increasing in India and particularly during the past decade. But, the job market failed to receive sufficient number of qualified engineers. At present, after having a suitable syllabus (for example, JNTUH which is skills-based) and teacher's effort, technical students lack the required communication skills. It is necessary to shift from the present skills-based approach to content based approach, wherever possible and necessary.

Though there are a number of ways to teach communication skills, some more methods can be introduced for the better results from the employment point of view. Technical students are habituated to learn the course material through the content, even if the present language classrooms are skills-based. Through the content, students' attention could be drawn easily towards language learning.

\subsection{Objectives}

- $\quad$ To suggest possible methods to introduce content-based instruction (CBI) for the development of communication skills of technical students

- $\quad$ To provide the possible links between the students, and through new teaching methods.

\subsection{What is $C B I$ ?}

"Content in CBI, is some kind of subject matter related to the students' own academic curriculum. The second language can be consequently used as the medium of instruction for any academic subject at any educational context or level" (Dauenas, 2004). 
"The focus of a CBI lesson is on the topic or subject matter. They learn about this subject using the language they are trying to learn, as a tool for developing knowledge and so they develop their linguistic ability in the target language" (Peachey, 2016).

'Content-based instruction', 'English across the curriculum' and 'Bilingual education' are different forms of CLIL (Content and Language Integrated Learning) (Darn, 2016).

To summerise, the content of CBI can be the subject matter which is of students' choice, and language helps as a medium for learning content.

\section{Reasons for incorporating content in language curriculum}

"language as a medium for learning content and content as a resource for learning and improving language" (Stoller, 2002).

Content is meaningful and understandable since it is drawn from the context relevant and appropriate to the age, interest and cognitive level of the learners (Omoto and Nyongesa 2013). Students are exposed to a large amount of chosen content, apart from learning the content contextually.

The following lines are summerised from Stoller \& Grabe (1997):

- In CBI classrooms, students are exposed to required amount of language while learning content. Thus, the language learning activities are natural and meaningful.

- CBI supports relevant, purposeful and contextualised language learning.

- Students in CBI classes have additional opportunities to use the content knowledge and expertise.

- Students are exposed to complex information and are involved in demanding activities which can lead to intrinsic motivation.

- In a natural way CBI supports cooperative learning

- CBI allows greater flexibility and adaptability to be built into the curriculum and activity sequences.

- Students have opportunities to choose specific content.

\section{Various methods to introduce CBI}

There are several methods to introduce CBI in the curriculum. Some of them are mentioned in the following paragraphs.

\subsection{Theme-based method}

In this method, courses are autonomous and allow a high degree of flexibility in terms of content selection, curricular organization and procedural application. Teachers operate independently without any organizational or institutional adjustments. A standard theme-based course would consist of a number of subunits focused on different topics which explore more specific aspects or different perspectives of the general theme. Topics should be arranged to provide maximum coherence for theme unit, and to generate a range of opportunities to explore both content and language. Each course is a sequence of topics linked together by the assumption of a coherent overall theme (Dauenas, 2004).

\subsection{Multi-disciplinary method}

"Combining or involving several academic disciplines or professional specializations in an approach to a topic or problem" (Oxford, 2016). Multidisciplinary approach has many advantages.

Language skills can be updated through workshops, seminars, training sessions - which are content loaded-from time to time. 
Regular practice of communication skills such as practice sessions on JAM, GD, PPTs will enable them gain confidence and eventually lead to their career development. Content of these sessions can be from the students' technical subjects.

\subsection{Multi-media method}

The aim of the multi-media approach is to facilitate computer-aided multi-media instruction enabling individualized and independent language learning through the students' choice of content. Students can understand peculiarities of language through audio- visual experience, for example, listening to standardised audio- visual inputs such as BBC website and answer the comprehension questions.

For the practice of productive skills -making presentations and oral reports, engaging in discussions and debates, giving oral or written response to questions or issues associated to the topics, writing summaries, commentaries, etc. In this way, skills and language analysis are integrated around the selected topics in a meaningful, coherent and interlinked way (Dauenas, 2004).

\subsection{Interdisciplinary method}

Materials for the interdisciplinary approach are selected in such a way that they would progressively increase their degree of difficulty, complexity, and challenging nature (Dauenas, 2004). For example, newspapers and magazine articles, political speeches, poems, short stories, interviews, business letters, recipes, and tourist brochures, etc.

\subsection{Incorporating some other teaching practices into $C B I$}

To incorporate other teaching practices into content-based instruction, a teacher can integrate project work (Stoller, 1997), make use of graphics, and incorporate computer technology (the internet) into the content-based classroom (Kasper, 2000). Integrating project work for the improvement of communication skills of technical students- students analyse a project work in the target language by discussions in groups, make a report by using a pre-designed questionnaire, and give a presentation.

\section{What are the advantages of content-based instruction? (Peachey, 2016)}

- It can make learning a language more interesting and motivating. Students can use the language to fulfil a real purpose, which can make students both more independent and confident.

- Students can also develop a much wider knowledge of the world through CBI which can feed back into improving and supporting their general educational needs.

- $\mathrm{CBI}$ is very popular among EAP (English for Academic Purposes) teachers as it helps students to develop valuable study skills such as note taking, summarising and extracting key information from texts.

- Taking information from different sources, re-evaluating and restructuring that information can help students to develop very valuable thinking skills that can then be transferred to other subjects.

- The inclusion of a group work element within the framework given above can also help students to develop their collaborative skills, which can have great social value.

Content of other subjects stimulates learners to think and learn English language. The use of content from other subjects makes English language sneak into the learners' cognition without pain. Content of other 
subjects offers opportunities for teachers to match the learners' interest and schemata with meaningful content thus facilitating the learning of language (Omoto and

Nyongesa, 2013)

\section{Barriers to implement new methods}

Opposition to language teaching by subject teachers may come from language teachers themselves. Subject teachers may be unwilling to take on the responsibility. There is little evidence to suggest that understanding of content is not reduced by lack of language competence. Current opinion seems to be that language ability can only be increased by content-based learning after a certain stage (Darn, 2016). Normally, language teachers are habituated to teach language as a skill-based course.

Teachers tend to separate language and subject matter thus making the learning of English difficult. Many teachers are not familiar with the use of CBI (Omoto and Nyongesa, 2013).

\section{Potential problems and possible solutions (Peachey, 2016)}

- Because CBI isn't explicitly focused on language learning, some students may feel confused or may even feel that they aren't improving their language skills. Deal with this by including some form of language focused follow-up exercises to help draw attention to linguistic features within the materials and consolidate any difficult vocabulary or grammar points.

- Particularly in monolingual classes, the overuse of the students' native language during parts of the lesson can be a problem. Because the lesson isn't explicitly focused on language practice students find it much easier and quicker to use their mother tongue. Try sharing your rationale with students and explain the benefits of using the target language rather than their mother tongue.

- It can be hard to find information sources and texts that lower levels can understand. Also the sharing of information in the target language may cause great difficulties. A possible way around this at lower levels is either to use texts in the students' native language and then get them to use the target language for the sharing of information and end product, or to have texts in the target language, but allow the students to present the end product in their native language. These options should reduce the level of challenge.

- Some students may copy directly from the source texts they use to get their information. Avoid this by designing tasks that demand students evaluate the information in some way, to draw conclusions or actually to put it to some practical use. Having information sources that have conflicting information can also be helpful as students have to decide which information they agree with or most believe.

\section{Discussion and Conclusion}

Many authors refer to successful program outcomes as evidence of its (CBI) benefits. They either describe a program that they assert as successful; or they discuss teacher and student interests, program enrollments, and successful student adjustment to later academic careers as support for CBI (Grabe and Stoller, 1997). For the past two decades CBI has developed its own success stories wherever it is implemented, it also works for our technical students. Teachers' have to choose an appropriate blend of content and language as per the interest and suitability of their students. 
The findings of Pessoa et. al. (2007) indicate that an effective content-based instruction class includes attention to both content and language through conversations that encourage student language use and development, as well as metalinguistic awareness by collaboratively negotiating form and by the teacher's feedback.

There also exists a set of well-documented standard models specifically developed to fulfill the particular needs and demands of different groups, settings and educational purposes. Moreover CBI crosses over disciplines and thematic spheres, providing a flexible teaching framework with optimal scope for the accommodation of the most diverse content areas (Dauenas, 2004). Flexibility in choosing content is one of the greatest pluses of CBI. This gives a wider scope for a teacher to explore more deep into CBI. Thus, a teacher can take maximum advantage for the benefit of students- before, after and during the class.

Content-based instruction is a powerful innovation in language teaching across a wide range of instructional contexts. There is a strong empirical support for CBI, and the success of many welldocumented programs offers additional support for the approach (Stoller and Grabe, 1997). Varied instructional contexts work as tools to incorporate different aspects of communication skills to technical students.

Numerous practical features of CBI make it an appealing curricular approach to language instruction (Stoller and Grabe, 1997). Thus, CBI has many features which can be easily molded to required shape to outpour maximum benefits to students. Teachers' job would become easier during the class to grab the attention of students easily. This leads to successful desired student outcome.

While CBI can be both challenging (Dauenas, 2004; Peachey, 2016) and demanding for the teacher and the students, it can also be very stimulating (Dauenas, 2004; Peachey, 2016) and rewarding (Peachey, 2016). Though CBI is highly flexible, a teacher should set up an outline for the proposed content for the desired student outcomes. The rewards of SBI are innumerable.

\section{References}

Darn Steve, 2016: Content and Language Integrated Learning https://www.teachingenglish.org.uk/article/content-language-integrated-learning

Dauenas Mar, 2004: The Whats, Whys, Hows and Whos of Content-Based Instruction in Second / Foreign Language Education, IJES, vol. 4 (1), 2004, pp. 73-96

Grabe William and Stoller L. Fredricka, 1997: Content-Based Instruction: Research Foundations, Copyright (c) 1997 Longman, Reprinted on the CoBaLTT website with permission. http://carla.umn.edu/cobaltt/modules/principles/grabe_stoller1997/READING1/foundation.htm

Kasper F Loretta, 2000: Theoretical Foundations and Pedagogical Applications Inn: Kasper F Loretta, Babbitt Marcia, Mlynarczyk William Rebecca, Brinton M. Donna, Rosenthal W. Judith 2000: Contentbased college ESL instruction, Lawrence Erlbaum Associates, New Jersy

Omoto Patrick Mulamba and Patrick Justus Nyongesa Wesonga, 2013: Content- Based Instruction: A Study of Methods of Teaching and Learning English in Primary Schools in Butula District International Journal of Business and Social Science Vol. 4 No. 5, 236-245pp 
Oxford, 2016: http://www.oxforddictionaries.com/definition/english/multidisciplinary

Retrieved on 23.04.2016

Peachey Nik, 2016: content-based instruction,

https://www.teachingenglish.org.uk/article/content-based-instruction retrieved on 05.05.2016

Pessoa Silvia, Hendry Heather, Donato Richard, Tucker Richard G, Lee Hyewon, 2007: Content-Based Instruction in the Foreign Language Classroom: A Discourse Perspective, Foreign Language Annals, Vol. 40, No. 1

Stoller F. (2002): Promoting the acquisition of knowledge in a content based course. In J. Crandall \& D. Kaufman (Eds.), Content-based instruction in higher education settings (pp. 109-123). Alexandria, VA: TESOL.

Stoller L. Fredricka and Grabe William, 1997: A Six-T's Approach to Content-Based Instruction1997 Longman,

http://www.carla.umn.edu/cobaltt/modules/curriculum/stoller_grabe19... 